\title{
The Association between Hemoglobin Value and Estimation of Amount of Intraoperative Blood Loss
}

\author{
Masoud Parish, Naghi Abedini*, Ata Mahmoodpoor, Morteza Gojazadeh, Haleh Farzin, \\ Samira Sadigi
}

Imam Reza Hospital, Tabriz, Iran

Email: *naghi26@yahoo.com

How to cite this paper: Parish, M., Abedini, N., Mahmoodpoor, A., Gojazadeh, M., Farzin, H. and Sadigi, S. (2017) The Association between Hemoglobin Value and Estimation of Amount of Intraoperative Blood Loss. Open Journal of Internal Medicine, 7 , 144-150

https://doi.org/10.4236/ojim.2017.74015

Received: October 1, 2017

Accepted: November 17, 2017

Published: November 20, 2017

Copyright $\odot 2017$ by authors and Scientific Research Publishing Inc. This work is licensed under the Creative Commons Attribution International License (CC BY 4.0).

http://creativecommons.org/licenses/by/4.0/

(c) (i) Open Access

\begin{abstract}
Introduction: The estimation of blood loss rate during surgery for prediction of transfusion of blood or blood products requirement is important for surgeon and anesthesiologist. In regard to various results and lack of definite index for start of transfusion in operating rooms, the assessment of blood loss reduction is necessary. The aim of study was evaluation of hemoglobin $(\mathrm{Hb})$ value and hemorrhage estimation rate. Methods and materials: 48 cases underwent major orthopedic surgery with high probability of intraoperative blood loss rate was included in study. $\mathrm{Hb}$, hematocrit (Hct) and basic vital signs were measured preoperatively and blood loss rate was estimated by using of blood volume in suction, bloody gases and blood loss in operation field and recorded. The blood sample per $100 \mathrm{~mL}$ blood loss was sent to laboratory. For transfusion deciding based on $\mathrm{Hb}$, we did not any intervention. Results: 26 males and 22 females were included in study. Our results showed that $\mathrm{Hb}$ value of males was higher significantly of females in preoperative period. After beginning of blood loss, $\mathrm{Hb}$ and Hct values declined with fixed slope and there was high negative correlation between them. First, intraoperative systolic and diastolic pressures declined with high slope and then reduced with mild slope. $\mathrm{Hb}$ value reduced significantly per $100 \mathrm{~mL}$ blood loss. During survey, no alteration in urine output did not be observed. Conclusion: Present study showed that much more intraoperative blood loss could reduce $\mathrm{Hb}$ with high correlation coefficient and measurement of it is efficient on transfusion.
\end{abstract}

\section{Keywords}

Hemoglobin, Transfusion, Estimated Blood Loss 


\section{Introduction}

Currently, transfusion is an important challenge in operating room. Transfusion is usually a result of intraoperative blood loss. During some of surgeries, this practice is not performed proportionally and correctly. Specialists have various opinions about this. This discrepancy leads to frequent and sometimes, unnecessary transfusions [1] [2]. Over decades, evidences showed that transfused patients expose with different adverse events (particularly, allogeneic blood) [1] [2] [3] [4] [5] such as postoperative pneumonia, sepsis and death [3]. American association of blood bank (AABB) recommended restricted transfusion [4] and many authors strictly appreciated on transfusion when $\mathrm{Hb}<8 \mathrm{gr} / \mathrm{dL}$ (i.e. $\mathrm{Hb}>10 \mathrm{gr} / \mathrm{dL}$ is not suitable for transfusion) [5] [6]. However, estimation and prediction of exact amount of blood loss is very important, more exact estimation could help surgeon and anesthesiologist for overcoming on possible risks during procedure [7]. Up to date, any definite indicator had not been found that could determinate what patient would need to transfusion and how much blood would require? Overall, transfusion is controversy. Main reason is referred to lack of specialty acceptance of guidelines because they are not based on evidences [8]. Therefore, the assessment of transfusion amount reduction strategies is necessary in regard to several results and absence of definite index for start of transfusion in OR. The aim of present study is evaluation of $\mathrm{Hb}$ value and estimation of amount of blood loss.

\section{Methods and Material}

This descriptive clinical trial was conducted on patients (ASA 1\&2) undergoing major orthopedic procedure with probability of intraoperative bleeding. The study was approved by ethical committee of Tabriz University of medical sciences and faculty of medicine; and informed written consent was obtained. All the patients during designed study time were included. In regard to lack of same studies, we used results of pilot studies for calculation of sample size. In 12 cases, the presence of association and its severity between intraoperative $\mathrm{Hb}$ and need to blood transfusion were assessed and evaluated. Then, sample size was determined to 48 cases with considering $\alpha=0.05,80 \%$ power and acceptable difference of P-value $<0.05$. Patients with known cardiopulmonary disease, risk of insufficient oxygenation of tissues, and patients with $\mathrm{Hb}<10 \mathrm{gr} / \mathrm{dL}$ were excluded from study [5]. We did not transfuse any blood preparation during surgery and if, we excluded them from study. Selected patients received general anesthesia after premedication with fentanyl and midazolam. Anesthesia was maintained by 2 to 3 $\mathrm{mg} / \mathrm{kg}$ propofol and $0.5 \mathrm{mg} / \mathrm{kg}$ atracurium and then, patients were intubated with proper size of endotracheal tube. In preoperative period, $\mathrm{Hb}$ and $\mathrm{Hct}$ values were routinely measured. Monitoring composed of non-invasive blood pressure measurement, heart rate, electrocardiogram, body temperature and urine output was performed. In intraoperative period, amount of blood loss was estimated by blood volume in suction, bloody gases and bloodshed in operation field in 4 stages 
and recorded. At the same time, a blood sample was sent to the lab to measure hemoglobin in proportion to a specific volume of bleeding with a $100-\mathrm{mL}$ frequency. For deciding to transfusion, we did not intervene based on $\mathrm{Hb}$ value and only the amounts of collected $\mathrm{Hb}$ on the basis of amount of bleeding at the same time were investigated for possible association of bleeding severity and probability of using it as an indicator for possible decision making for transfusion at the end of the study. Given data were analyzed by descriptive statistical methods (frequency, percentage and mean \pm standard deviation) and comparison test for independent groups and repeated measurements scheme test (Mauchly's test) and regression with SPSS 0.16 . P-value less than 0.05 was considered statistically significant.

This general mode scheme is a paired test. With the difference that instead of comparing a group in 2 situations, one group is compared in two or more situations. When the same measurements are taken for a few times by a subject, the analysis of variance with repeated measurements should be used to analyze the data and compare the mean of data between these groups. The default test is used for repeated measurements of the Mauchly's Test of Sphericity.

\section{Results}

48 cases ( 26 males and 22 females) with mean age of $43.34 \pm 20.59$ years old were included in study. In preoperative period, we measured variables such as blood pressure, heart rate, $\mathrm{Hb}$ and Hct values as basic measures which were considered as scale for further evaluations to have basis for comparison of upslope or downslope trend of these variables in postoperative period. We summarized preoperative $\mathrm{Hb}$ and $\mathrm{Hct}$ values in Table 1.

$22(45.83 \%), 17(35.42 \%)$ and $9(18.75 \%)$ undergone surgery due to femoral neck fracture, tibia fracture and replacement of knee, respectively. Our results showed that reached time to given bleeding volume (stage I: $100 \mathrm{~mL}$; stage II: $200 \mathrm{~mL}$ ) had statistically significant difference with other times (P-value $<0.001$ ) but reached time to bleeding volume (stage III: $300 \mathrm{~mL}$; stage IV: $400 \mathrm{~mL}$ ) had no significant difference with each other $(\mathrm{P}$-value $<0.19)$ (Table 2).

In given time interval to reach given blood volume, $\mathrm{Hb}$ value had no significant difference in relation to preoperative period. Although in other cases, mean $\mathrm{Hb}$ value had significant difference between 2 stages (i.e. significant decline of $\mathrm{Hb}$ mean value was associated with increased bleeding volume) (Table 2). Hct value, the

Table $1 . \mathrm{Hb}$ and Hct values in two genders.

\begin{tabular}{cccccccccc}
\hline & Number & & Min & & Max & & Mean & & P-value \\
\hline Gender & male & female & male & female & male & female & male & female & \\
\hline $\begin{array}{c}\text { Preoperative } \\
\text { Hb }\end{array}$ & 26 & 22 & 11.3 & 8.3 & 16.5 & 16.4 & 14.36 & 12.3 & $<0.001$ \\
$\begin{array}{c}\text { Preoperative } \\
\text { Hct }\end{array}$ & 26 & 22 & 27.6 & 24.2 & 49.7 & 50.2 & 44 & 37.2 & $<0.001$ \\
\hline
\end{tabular}


Table 2. The reached time to given bleeding time.

\begin{tabular}{cc}
\hline Time (minute) & Mean \pm standard deviation \\
\hline Reached time to $100 \mathrm{~mL}$ bleeding volume & $32.46 \pm 26.62$ \\
Reached time to $200 \mathrm{~mL}$ bleeding volume & $52.06 \pm 35.18$ \\
Reached time to $300 \mathrm{~mL}$ bleeding volume & $74.23 \pm 45.14$ \\
Reached time to $400 \mathrm{~mL}$ bleeding volume & $86.40 \pm 32.05$ \\
\hline
\end{tabular}

${ }^{\star} \mathrm{P}<0.001$.

same as $\mathrm{Hb}$ value, had no significant difference with preoperative period until 100 $\mathrm{mL}$ bleeding volume. But in other cases, mean of Hct value had significant difference (i.e. significant decline of Hct mean value was associated with increased bleeding volume) (Figure 1).

There was no significant difference between heart rate and various bleeding volumes.

At least, mean of systolic/diastolic pressures had significant difference in 4 groups as follows: mean of systolic pressure had significant decline except in 300 $\mathrm{mL}$ bleeding volume. On the other hand, comparisons demonstrated that slope of decline trend of mean diastolic blood pressure was gradually slow (Figure 2).

Pre and intraoperative urine output was defined in bleeding volume. There were significant differences among mean of urine volumes in each stage ( $\mathrm{P}$-value $<0.001$ ). Table 3 shows urine output volumes in 4 stages. The authors summarized the Mean Heart rate systolic and diastolic pressures in 4 stages in Figure 3.

\section{Discussion}

One of intraoperative challenges, especially in orthopedic surgeries is blood loss. Present study showed that when blood loss reached to $100 \mathrm{~mL}$ at mean of 29 minutes of procedure and along with, $\mathrm{Hb}$ values started to decline. Despite of higher $\mathrm{Hb}$ values in males before surgery, $\mathrm{Hb}$ and $\mathrm{Hct}$ values started to decline with fixed slope in two genders. Accordingly, $\mathrm{Hb}$ value after $300 \mathrm{~mL}$ blood loss reduced 1.5 unite in relation to basic measures. Therefore, we can predict possibly when patients will need to transfusion if we have basic $\mathrm{Hb}$ value. Robinson et al showed that intraoperative transfusion was highly related to primary hemoglobin [2]. Patients with lower $\mathrm{Hb}$ value had much more requirement to transfusion. So, aged patients and women required transfusion due to lower basic $\mathrm{Hb}$ value [2]. Rogers MA et al suggested that women received much more transfusion than men during heart operations [9] and Rummassk and Chen showed gender effect on amount of blood loss and higher transfusion in females [10] [11]. Murray et al used Hct measurement and blood gas analysis for confirmation of estimated blood and fluid loss [12] [13]. They concluded Hct $<25 \%$ was w threshold for transfusion [12]. Hemodynamic monitoring is a central component of intensive care. Hemodynamic variables often suggest hypovolemic and etiologies to cardiovascular insufficiency, thus it may be an effective manner in estimation of 


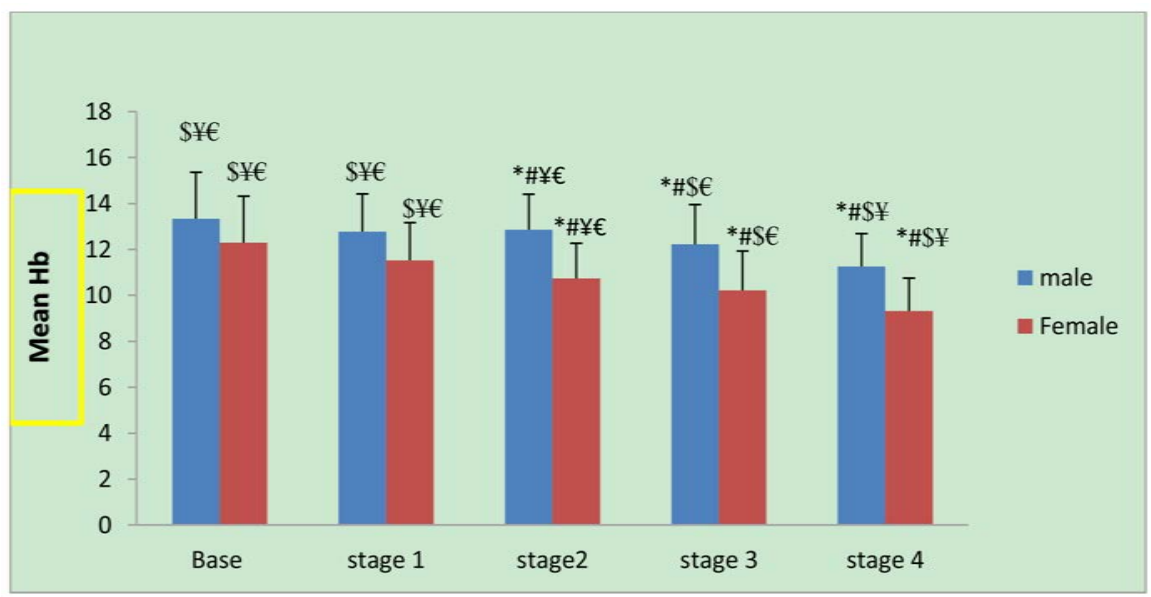

Figure 1. Mean $\mathrm{Hb}$ values in 4 stages: ${ }^{\star} \mathrm{P}<0.05$ vs Base $\mathrm{Hb}, \# \mathrm{P}<0.05$ vs stage $1, \$ \mathrm{P}<0.05$ vs stage $2, ¥ \mathrm{P}<0.05$ vs stage $3, € \mathrm{P}<0.05$ vs stage 4 .

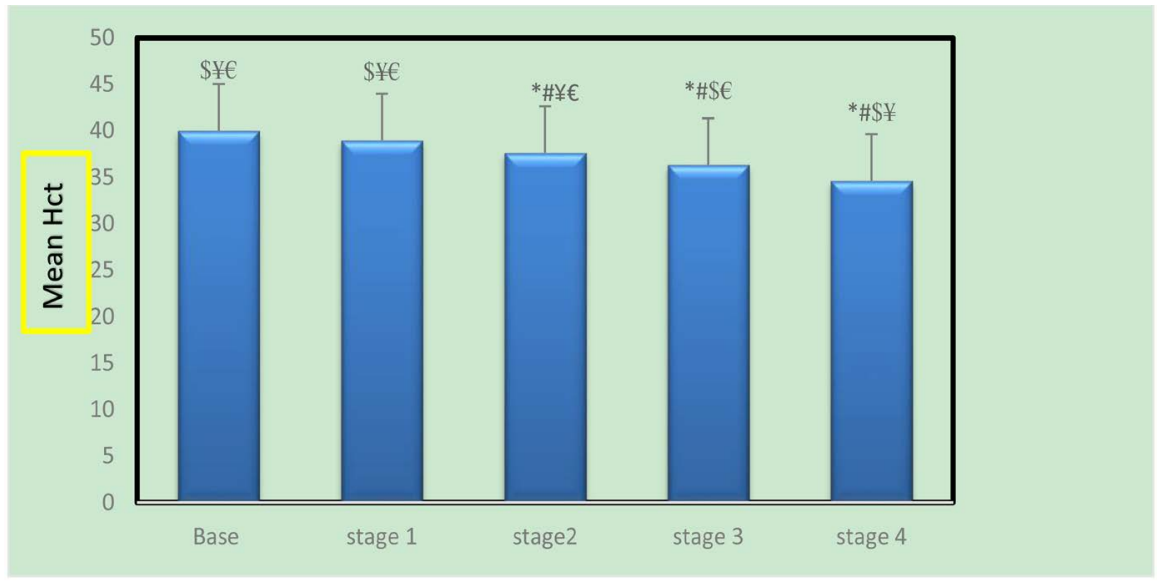

Figure 2. Mean Hct values in 4 stages: ${ }^{\star} \mathrm{P}<0.05$ vs $\mathrm{Base} \mathrm{Hb}, \# \mathrm{P}<0.05$ vs stage $1, \$ \mathrm{P}<$ 0.05 vs stage $2, \mathrm{P}<0.05$ vs stage $3, € \mathrm{P}<0.05$ vs stage 4 .

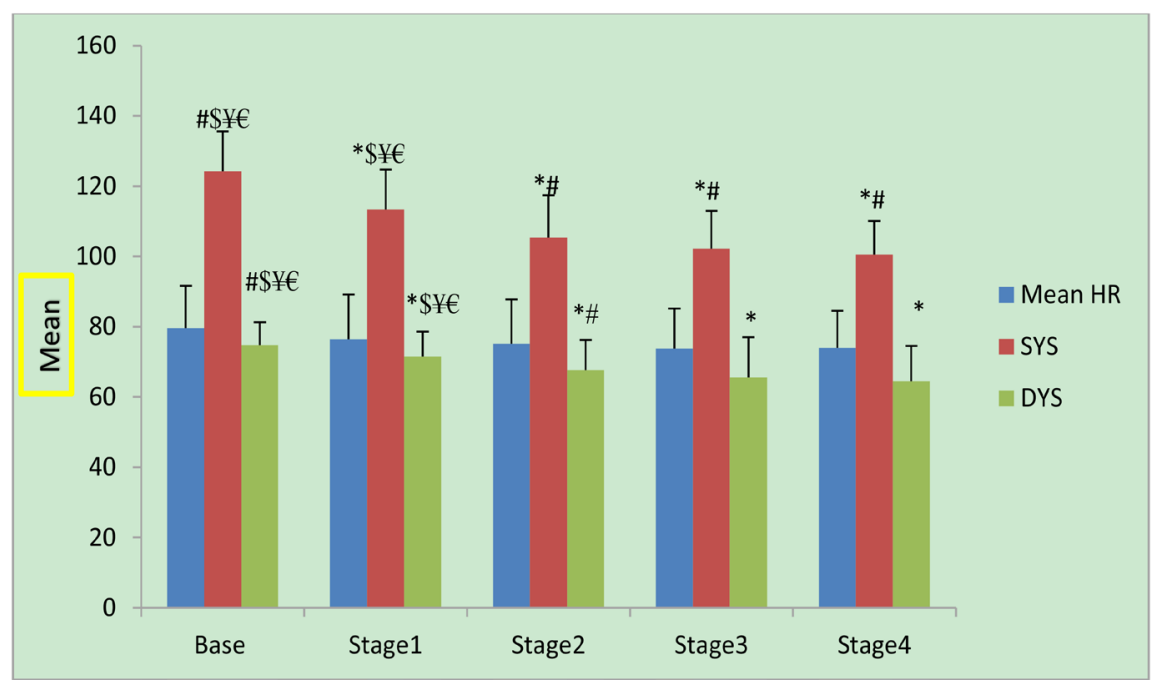

Figure 3. Mean Heart rate systolic and diastolic pressures in 4 stages: ${ }^{\star} \mathrm{P}<0.05$ vs Base $\mathrm{Hb}, \# \mathrm{P}<0.05$ vs stage $1, \$ \mathrm{P}<0.05$ vs stage $2, ¥ \mathrm{P}<0.05$ vs stage $3, € \mathrm{P}<0.05$ vs stage 4 . 
Table 3. The mean of urine volumes in 4 stages.

\begin{tabular}{cc}
\hline Urine volumes $(\mathrm{mL})$ & Mean \pm standard deviation \\
Urine volume before surgery & $229.33 \pm 127.6$ \\
Urine volume at $100 \mathrm{~mL}$ bleeding volume & $279 \pm 141.94$ \\
Urine volume at $200 \mathrm{~mL}$ bleeding volume & $299.66 \pm 148.67$ \\
Urine volume at $300 \mathrm{~mL}$ bleeding volume & $334 \pm 148.73$ \\
Urine volume at $400 \mathrm{~mL}$ bleeding volume & $366 \pm 152.26$ \\
\hline
\end{tabular}

${ }^{*} \mathrm{P}<0.001$

blood loss [13]. Present study showed systolic/diastolic pressure reduced during surgery and parallel with blood loss, which seems to be a normal event. Robinson et al showed blood pressure and heart rate (HR) were high before surgery due to probably stress, then HR reduced over time because of induction of anesthesia or reduction of patient's stress. It is obvious that increased blood loss correlates with increased HR that compensatory mechanisms is to increase cardiac output and maintain perfusion pressure [14]. Also, estimating blood loss is complicated by other factors including urinary losses that help to guide volume replacement, hemorrhage. In this study, slope of urine volume was homogenous; it indicated proper hydration during surgery, so application of hydration guidelines during conventional operations even with major bleeding maintains normal circulation.

\section{Conclusion}

Hemoglobin concentration may be therapeutic guide in actively bleeding patients and we can predict requirement of transfusion with measurement of $\mathrm{Hb}$ values and intraoperative blood loss. Therefore, this practice has positive effect on transfusion.

\section{References}

[1] Mirjani, S.J., Sharifianatar, A. and Eshghpour, M. (2016) Evaluation and Comparison of Blood Loss during Different Ortognathic Surgeries. Journal of Mashhad Dental School, 40, 159-166.

[2] Robinson, S., McGonigle, O., Volin, S., Sung, Y.-C., Moore, M., Cassidy, C., et al. (2013) Comprehensive Look at Blood Transfusion Utilization in Total Joint Arthroplasty at a Single Academic Medical Center under a Single Surgeon. Journal of Blood Transfusion, 2013, Article ID:983250.

[3] Hassani, V., Rahimzadeh Bajgiran, P., Kadivar, M. and Attarchi, Z. (2005) Comparison of Hemodynamic Changes of Autologous Blood Transfusion with Hemologous Transfusion in Patients Undergoing Elective Orthopedic Surgery under General Anesthesia. Razi Journal of Medical Sciences, 12, 91-96.

[4] Fisher, E.S., Shortell, S.M., Kreindler, S.A., Van Citters, A.D. and Larson, B.K. (2012) A Framework for Evaluating the Formation, Implementation, and Performance of Accountable Care Organizations. Health Affairs, 31, 2368-2378. https://doi.org/10.1377/hlthaff.2012.0544

[5] Niraj, G., Puri, G., Arun, D., Chakravarty, V., Aveek, J. and Chari, P. (2003) As- 
sessment of Intraoperative Blood Transfusion Practice during Elective Non-Cardiac Surgery in an Indian Tertiary Care Hospital. British Journal of Anaesthesia, 91, 586-589. https://doi.org/10.1093/bja/aeg207

[6] Nuttall, G., Brost, B., Connis, R., Gessner, J., Harrison, C., Miller, R., et al. (2006) Practice Guidelines for Perioperative Blood Transfusion and Adjuvant Therapies: An Updated Report by the American Society of Anesthesiologists Task Force on Perioperative Blood Transfusion and Adjuvant Therapies. Anesthesiology, 105, 198-208. https://doi.org/10.1097/00000542-200607000-00030

[7] Yu, C., Chow, T., Kwan, A., Wong, S. and Fung, S. (2000) Intra-Operative Blood Loss and Operating Time in Orthognathic Surgery Using Induced Hypotensive General Anaesthesia: Prospective Study. Hong Kong Medical Journal, 6, 307-311.

[8] Ferraris, V.A., Davenport, D.L., Saha, S.P., Austin, P.C. and Zwischenberger, J.B. (2012) Surgical Outcomes and Transfusion of Minimal Amounts of Blood in the Operating Room. Archives of Surgery, 147, 49-55. https://doi.org/10.1001/archsurg.2011.790

[9] Rogers, M.A., Blumberg, N., Saint, S., Langa, K.M. and Nallamothu, B.K. (2009) Hospital Variation in Transfusion and Infection after Cardiac Surgery: A Cohort Study. BMC Medicine, 7, 37. https://doi.org/10.1186/1741-7015-7-37

[10] Rummasak, D., Apipan, B. and Kaewpradup, P. (2011) Factors That Determine Intraoperative Blood Loss in Bimaxillary Osteotomies and the Need for Preoperative Blood Preparation. Journal of Oral and Maxillofacial Surgery, 69, e456-e460. https://doi.org/10.1016/j.joms.2011.02.085

[11] Chen, C.-M., Lai, S.S.-T., Hsu, K.-J., Lee, H.-E. and Huang, H.-L. (2011) Assessment of the Related Factors of Blood Loss and Blood Ingredients among Patients under Hypotensive Anesthesia in Orthognathic Surgery. Journal of Craniofacial Surgery, 22, 1594-1597. https://doi.org/10.1097/SCS.0b013e31822e5edb

[12] Murray, D.J., Pennell, B.J., Weinstein, S.L. and Olson, J.D. (1995) Packed Red Cells in Acute Blood Loss: Dilutional Coagulopathy as a Cause of Surgical Bleeding. Anesthesia \& Analgesia, 80, 336-342.

[13] Pinsky, M.R. and Payen, D. (2005) Functional Hemodynamic Monitoring. Critical Care, 9, 566. https://doi.org/10.1186/cc3927

[14] Gutierrez, G., Reines, H. and Wulf-Gutierrez, M.E. (2004) Clinical Review: Hemorrhagic Shock. Critical Care, 8, 373. https://doi.org/10.1186/cc2851 